\title{
Contribuições da metodologia das produções narrativas na licenciatura em educação do campo ${ }^{i}$
}

\author{
Contributions of the methodology of narrative productions in the degree in \\ rural education
}

\section{Contribuciones de la metodología de las producciones narrativas en la licenciatura en educación del campo}

\author{
Marcelo Loures dos Santos ${ }^{2}$ \\ Diego Gonzaga Duarte da Silva ${ }^{3}$
}

\begin{abstract}
Resumo: As Licenciaturas em Educação do Campo buscam formar educadores para atuarem nas escolas do campo. São orientadas por processos formativos em alternância, articulando formação na universidade e na comunidade dos educandos. Criar estratégias para a produção de conhecimento na articulação entre estes espaços é um de seus desafios. O objetivo desse artigo é avaliar, a partir do estudo de caso de uma educanda da Licenciatura em Educação do Campo da Universidade Federal de Viçosa, se essa metodologia pode favorecer a articulação entre experiências pessoais e saberes acadêmicos. Foram realizadas três entrevistas narrativas sobre os territórios educativos de sua comunidade, abordando trajetória pessoal, história e contexto local. As narrativas indicaram uma aproximação à lógica da formação por Área de Conhecimento; a articulação entre elementos vivenciais e sua contextualização histórica; e o papel dos sujeitos nas transformações sociais.
\end{abstract}

Palavras-chave: Licenciaturas em educação do campo. Metodologia das produções narrativas. Formação por alternância.

Abstract: The rural education degree courses aim to train teachers to work in the rural schools. They are oriented by alternating formative processes, articulating formation in the university and in the community of the students. Creating strategies to produce knowledge in the articulation between these spaces is one of its challenges. The purpose of this article is to evaluate, from the case study of a student of the Degree in Field Education of the Federal University of Viçosa, if this methodology can favor the articulation between personal experiences and academic knowledge. Three narrative interviews were conducted about her educational experiences in her community, addressing personal trajectory, history and local context. The narratives indicated an approximation to the logic of training by Area of Knowledge; the articulation between experiential elements and their historical contextualization; and the role of subjects in social transformations.

Keywords: Methodology of narratives productions. Pedagogy of alternating. Rural education.

Resumen: Las Licenciaturas en Educación del Campo buscan formar educadores para actuar en escuelas del campo. Se orientan por procesos formativos en alternancia, articulando formación en la universidad y en la comunidad de los educandos. Crear estrategias para la producción de conocimiento en la articulación entre estos espacios es uno de sus desafíos. El objetivo de este artículo es evaluar, a partir del estudio de caso de una educanda de la Licenciatura en Educación del Campo de la Universidad Federal de Viçosa, si esa metodología puede favorecer la articulación entre experiencias personales y saberes académicos. Se realizaron tres entrevistas narrativas sobre los territorios educativos de su comunidad, abordando trayectoria personal, historia y contexto local. Las narrativas indicaron una aproximación a la lógica de la formación por Área de Conocimiento; la articulación entre elementos vivenciales y su contextualización histórica; y el papel de los sujetos en las transformaciones sociales.

\footnotetext{
${ }^{1}$ Submetido em: 31 mar. 2019 - Aceito em: 21 out. 2019 - Publicado em: 24 dez. 2019

${ }^{2}$ Universidade Federal de Ouro Preto (UFOP) - E-mail: marceloloures.cead@ gmail.com

${ }^{3}$ Universidade Federal de Viçosa (UFV) - E-mail: diegoduartegeo@gmail.com
} 
Palabras clave: Educación del campo. Metodología de las producciones narrativas. Pedagogía de la alternancia.

\section{Introdução}

O regime de formação em alternância existente nos cursos de Licenciatura em Educação do Campo, situados em diversas Instituições de Ensino Superior brasileiras, busca desenvolver processos formativos capazes de estimular os futuros educadores do campo a exercerem uma atuação profissional que articule os processos educativos vivenciados no meio acadêmico aos vivenciados no cotidiano de suas comunidades de origem (MOLINA; SÁ, 2011). É por meio do processo formativo em alternância, organizado entre atividades desenvolvidas nas Instituições de Ensino Superior (Tempo Escola) e nas comunidades (Tempo Comunidade), que se busca a articulação dessas experiências. Nesse processo formativo, um dos objetivos do regime de alternância é criar estratégias, a partir da articulação universidade/comunidade/território e da dialética entre teoria e prática, para que os educandos consigam refletir e intervir sobre as dinâmicas sociais existentes nos meios sociais em que vivem (MOLINA; ANTUNES-ROCHA, 2014). Sob essa perspectiva, a alternância desenvolvida nas Licenciaturas em Educação do Campo tem como princípio auxiliar os educandos do curso a se inserirem nas dinâmicas sociais existentes em seus territórios para desenvolverem processos educativos coletivos, envolvendo suas famílias e comunidades (CARVALHO; SILVA, 2018).

Em contrapartida, Carvalho e Silva (2018) sugerem que um dos desafios ao regime de alternância desenvolvido em algumas Licenciaturas em Educação do Campo refere-se às dificuldades em articular os processos formativos dos Tempos Escola aos dos Tempos Comunidade. Tais dificuldades, segundo as autoras, estão associadas à ausência do acompanhamento dos Tempos Comunidades pelos educadores dos cursos e, também, pela complexidade das dinâmicas sociais vivenciadas pelos educandos em suas comunidades e territórios educativos. Assim, há a necessidade de se criar estratégias capazes de promover maior articulação e integração dos processos educativos existentes nas diferentes comunidades e territórios de vivência dos educandos (CARVALHO; SILVA, 2018), contribuindo para o desenvolvimento de um processo formativo que se articule e se integre às lutas, às culturas, às formas de trabalho e às dinâmicas sociais dos povos do campo.

Considerando tais afirmações, é de suma importância que a matriz curricular das Licenciaturas em Educação do Campo desenvolva metodologias de trabalho que favoreçam o reconhecimento da complexidade inerente aos contextos sócio-históricos dos seus educandos (MOLINA, 2017). A Metodologia das Produções Narrativas (MPN) apresenta-se neste contexto como uma importante ferramenta pedagógica para o desenvolvimento dos processos educativos no âmbito das Licenciaturas em Educação do Campo por possibilitar, na elaboração das narrativas, a articulação de contextos biográficos, históricos e sociais dos educandos (FANTASIA; LEITE, 2013).

A MPN, conforme proposta de Balasch e Montenegro (2003), fundamenta-se na perspectiva dos Conhecimentos Situados, quando considera que todo indivíduo ao narrar, 
parte de uma perspectiva parcial sobre as realidades em que vive, permitindo-lhe evidenciar suas especificidades culturais, os processos educativos e as práticas sociais existentes nos contextos sociais investigados (BALASCH; MONTENEGRO, 2003; MARTÍNEZ; TARRÉS, 2003). É sob essa concepção que acreditamos que a MPN pode auxiliar os educandos das Licenciaturas em Educação do Campo a refletirem sobre a realidade vivenciada, construindo interpretações e o encadeamento de eventos micro e macro históricopolíticos em suas comunidades. Dessa maneira, estariam mais aptos a propor ações para as melhorias que se fizerem necessárias nos territórios em que vivem, cumprindo, assim, um dos objetivos dos processos formativos em alternância.

Reconhecendo, portanto, a necessidade de promover estratégias que articulem os contextos sociais vivenciados pelos educandos em seus meios de vivência aos processos de formação das Licenciaturas em Educação do Campo, no presente artigo, abordamos as contribuições da MPN como ferramenta pedagógica para o curso de Licenciatura em Educação do Campo (LICENA) da Universidade Federal de Viçosa (UFV). Em termos metodológicos, trata-se de um estudo de caso, para o qual foram realizadas três entrevistas narrativas com uma educanda da turma de 2014 da LICENA, buscando identificar e aprofundar as experiências educativas vivenciadas por ela em seu território de vivência. Ao término de cada entrevista, a educanda redigia sua narrativa e a enviava ao pesquisador. Após avaliar as narrativas recebidas, o pesquisador formulava questões à educanda. Na primeira narrativa, as questões buscaram promover e ampliar as reflexões sobre sua trajetória de vida; na segunda, os contextos sociais em que vivia, ampliando a narrativa anterior; e, na última, as articulações possíveis com os conteúdos acadêmicos demandados para aquela atividade e sua articulação com as discussões anteriores.

Assim, situando-se como um estudo de caso que analisa as contribuições da MPN como ferramenta pedagógica para a LICENA, o presente artigo está organizado em quatro seções, além desta introdução. Na primeira, destacamos os processos de formação em alternância nas Licenciaturas em Educação do Campo, apresentando os contextos históricos que possibilitaram a sua constituição; na segunda, evidenciamos os princípios da MPN, apresentando seus objetivos e as etapas a serem realizadas ao longo do processo de investigação; na terceira, apresentamos as narrativas elaboradas pela participante da pesquisa e como a MPN foi utilizada como ferramenta pedagógica na LICENA; e, na última seção, apresentamos as nossas considerações finais.

\section{A formação nos cursos de licenciaturas em educação do campo}

Nos últimos anos, as lutas e reivindicações dos movimentos sociais e sindicais camponeses para melhorias da educação destinada aos povos do campo garantiram o desenvolvimento de políticas públicas específicas para a formação de educadores do campo, como o Programa Nacional de Educação na Reforma Agrária (Pronera), vinculado ao Ministério do Desenvolvimento Agrário (MDA), e o Programa de Apoio à Formação Superior em Licenciatura em Educação do Campo (Procampo), no âmbito do Ministério da Educação (MOLINA; ANTUNES-ROCHA, 2014). 
Especificamente, em relação ao Procampo, o programa foi criado em 2006, possibilitando a criação das Licenciaturas em Educação do Campo, com o intuito de promover a formação de educadores para atuação nos anos finais do Ensino Fundamental e Ensino Médio das escolas de educação básica do campo (SANTOS, 2012). As primeiras Licenciaturas em Educação do Campo iniciaram suas atividades a partir do ano de 2007, como experiências piloto em quatro Universidades Federais indicadas pelos movimentos sociais e sindicais camponeses: Universidade de Brasília, Universidade Federal de Minas Gerais, Universidade Federal da Bahia e Universidade Federal de Sergipe (MOLINA; ANTUNES-ROCHA, 2014; MOLINA, 2015).

As experiências desenvolvidas nessas quatro universidades possibilitaram que a oferta das Licenciaturas em Educação do Campo servisse de lastro à concepção de formação para educadores para atuarem na Educação do Campo, orientando sua ampliação para outras Instituições de Ensino Superior no Brasil, a partir da publicação de Editais Públicos nos anos de 2008 e 2009, por intermédio da Secretaria de Educação Continuada, Alfabetização, Diversidade e Inclusão (Secadi). Contudo, os Editais de 2008 e 2009 ampliaram a oferta de 32 cursos de Licenciatura em Educação do Campo, mas como projetos especiais, autorizados para o desenvolvimento de uma única turma. Somente com o Programa Nacional de Educação do Campo (Pronacampo), em 2012, é que ocorre, mediante aprovação nas instituições de ensino superior, a garantia de continuidade e permanência das Licenciaturas em Educação do Campo no território brasileiro. Por meio do Edital MEC/SESU/SETEC/SECADI n. ${ }^{\circ}$ 02/2012, são criadas 42 novas Licenciaturas em Educação do Campo nas regiões Sudeste, Centro-Oeste, Nordeste, Norte e Sul do Brasil (MOLINA; ANTUNES-ROCHA, 2014; MOLINA, 2015).

As Licenciaturas em Educação do Campo inauguram uma modalidade de graduação que promove a formação inicial de educadores do campo para "uma atuação profissional que vai além da docência, que tenham condições de trabalhar também na gestão dos processos educativos que acontecem na escola e no seu entorno" (MOLINA; SÁ, 2011, p. 36). Em suas análises, Molina e Sá (2011) destacam que as Licenciaturas em Educação do Campo buscam desenvolver, ao longo de seu processo de formação, metodologias integradas aos contextos sociais dos povos do campo, contribuindo para que os futuros educadores desenvolvam práticas pedagógicas articuladas às lutas dos movimentos sociais e sindicais que atuam com os povos do campo. Para isso, é necessário um modelo de formação que possibilite aos educadores o desenvolvimento de uma atuação profissional articulada aos processos educativos escolares e não escolares, integrando dimensões da vida cotidiana à vida escolar.

Buscando integrar as dimensões da vida cotidiana à vida escolar, os processos formativos no âmbito das Licenciaturas em Educação do Campo ocorrem em regime de alternância, dividindo os tempos e espaços de formação entre Tempo Escola e Tempo Comunidade (MOLINA; ANTUNES-ROCHA, 2014). O Tempo Escola é o período no qual os educandos se encontram nas Instituições de Ensino Superior, assistindo aulas, recebendo orientações, relatando experiências e desenvolvendo atividades de ensino, pesquisa e extensão de naturezas diversas; enquanto que o Tempo Comunidade é o espaço em que se busca articular as atividades acadêmicas com suas atividades agrícolas, de militância nos 
movimentos sociais e sindicais, de atuação nas escolas do campo, dentre outras atividades realizadas em suas comunidades e territórios de origem. Essa articulação entre Tempo Escola e Tempo Comunidade é fundamental para o desenvolvimento de práticas educativas articuladas aos modos de vida dos povos do campo (CARVALHO; SILVA, 2018).

A fim de promover a articulação entre o Tempo Escola e o Tempo Comunidade, as Licenciaturas em Educação do Campo utilizam em seu processo de formação em alternância instrumentos pedagógicos diversos. Especificamente em relação à LICENA, alguns dos instrumentos pedagógicos utilizados, conforme análise do Projeto Pedagógico do Curso (UFV, 2013), são os Planos de Estudo, as Colocações em Comum, os Cadernos da Realidade, as Viagens e Visitas de Estudo, as Intervenções Externas, as Atividades de Retorno e Experiências, os Projetos Profissionais e os Serões de Estudo (UFV, 2013). Esses instrumentos pedagógicos, em sua origem, foram incorporados a partir da experiência da Pedagogia da Alternância desenvolvida no âmbito dos Centros Familiares de Formação por Alternância (CEFFAs) e ressignificados para a formação inicial de educadores em regime de alternância no ensino superior.

Os Planos de Estudo são atividades de pesquisa propostas pelos educadores da LICENA a serem desenvolvidas pelos educandos durante o Tempo Comunidade com o objetivo de promover reflexões sobre os contextos sociais vivenciados a partir do levantamento de informações nos territórios de origem. As Colocações em Comum, por sua vez, são espaços formativos realizados no Tempo Escola com o objetivo de socializar as experiências vivenciadas pelos educandos durante o Tempo Comunidade, para definir temas a serem aprofundados nas disciplinas do curso. Os Cadernos da Realidade buscam auxiliar os educandos a organizar e sistematizar os conhecimentos produzidos e as reflexões que surgiram nos estudos e debates realizados tanto no Tempo Escola, quanto no Tempo Comunidade. As Viagens e Visitas de Estudo possibilitam que os educandos conheçam novas realidades sociais e profissionais, favorecendo a articulação entre as vivências acadêmicas e a experiência camponesa, seja nas escolas do campo, nos movimentos sociais ou nas práticas agrícolas. As Intervenções Externas, por seu turno, são realizadas por pessoas que não compõem o corpo docente da LICENA, por meio de cursos, palestras, seminários, dentre outras atividades, com o intuito de aprofundar determinados temas que surgiram na Colocação em Comum. As Atividades de Retorno e Experiências são processos formativos desenvolvidos pelos educandos durante o Tempo Comunidade para socializar com as comunidades as discussões e trabalhos realizados. Os Projetos Profissionais, por sua vez, buscam inserir os educandos no mundo do trabalho, a fim de promover reflexões sobre a sua atuação como educador do campo. Por fim, os Serões de Estudo são espaços formativos que ocorrem no período noturno, envolvendo atividades de cunho artístico, cultural, acadêmico e político (UFV, 2013).

Embora os instrumentos pedagógicos não possam ser pensados separadamente, para o desenvolvimento da Metodologia das Produções Narrativas, o Plano de Estudos têm um papel central, uma vez que define o tema que balizará as discussões de ensino, pesquisa e extensão, no Tempo Escola e no Tempo Comunidade. O tema adotado pelo Plano de Estudos durante a realização da pesquisa foi "Territórios Educativos", a partir do qual foram 
orientadas as entrevistas narrativas.

\section{Princípios da metodologia das produções narrativas}

A Metodologia das Produções Narrativas (MPN) é uma ferramenta metodológica desenvolvida a partir de uma gama ampliada de referenciais (BALASCH; MONTENEGRO, 2003). Uma de suas referências é Mikhail Bakhtin (1981), para quem todo conhecimento é produzido a partir de condições semióticas e materiais. Em outras palavras, toda ação humana é dialógica e produz-se, em um dado momento histórico, demarcada pelo modo de produção existente, entenda-se produção material e produção simbólica. Os posicionamentos assumidos por um sujeito podem encarnar a expressão de um sujeito coletivo. A teoria dos Conhecimentos Situados, de Donna Haraway (1995) também é uma referência importante para a MPN. Segundo ela, os conhecimentos são produzidos a partir da parcialidade de uma perspectiva, segundo o sujeito e sua localização em um dado contexto. As conexões estabelecidas entre os sujeitos envolvidos num processo relacional constituem e legitimam a parcialidade dos saberes, que orientará suas atitudes (HARAWAY, 1995).

Partindo desses pressupostos, Balasch e Montenegro (2003) desenvolvem a Metodologia das Produções Narrativas, cuja proposta se alicerça sobre os seguintes princípios: (1) os pesquisadores situam-se diante de sujeitos considerando uma multiplicidade de posições (e não apenas duas) em um dado momento e contexto; (2) as intervenções envolvem pessoas diretamente interessadas nas transformações propostas, na condição de sujeito participante, e não como expert; (3) os pesquisadores devem conceber as pessoas a partir de uma diversidade de experiências inseparáveis entre si, em uma multiplicidade de interações e oportunidades de ações; (4) as intervenções podem provocar transformações sociais sem a necessidade de uma leitura unificada de sujeitos/temas.

Considerando essas informações, os conhecimentos que surgem da MPN são produzidos por meio de um processo relacional, interessado e reflexivo. Relacional, porque envolve e é direcionado a partir de uma interação entre pesquisador e participante da pesquisa; interessado, porque representa um posicionamento do participante da pesquisa em relação às suas experiências e contextos sociais em que se insere; reflexivo, porque é pressuposto dos processos dialéticos de produção do conhecimento, ou seja, uma atualização permanente do que é narrado. Portanto, as experiências dos participantes da pesquisa são compreendidas como um conhecimento em construção que podem ser remanejadas e reinterpretadas a partir dos processos reflexivos e interativos provocados pelas narrativas. Em se tratando de sujeitos envolvidos nas ações de suas comunidades, espera-se que esta construção repercuta em suas ações e nas de seu grupo (GOIKOETXEA, 2014).

Em seu processo de construção, a MPN é desenvolvida a partir de entrevistas nas quais se discutem as experiências dos entrevistados em uma dada temática, em geral, objeto de estudo de um grupo de pesquisa ou investigação em andamento. Pesquisador e entrevistado dialogam sobre diversos aspectos do fenômeno estudado, considerando que o participante, nessa interação, relata, revisita e reconstrói suas experiências. Após cada sessão, 
o entrevistado apresenta sua narrativa ao pesquisador sobre as principais ideias discutidas. Com os acréscimos e/ou reparos, essas ideias serão apresentadas para o pesquisador que, ao avaliar o material, apresentará comentários e questões para o entrevistado sobre temas que teriam potencial para enriquecer a narrativa. Os comentários e as questões apresentadas pelo pesquisador orientam a retomada da entrevista seguinte, sendo a narrativa anterior esclarecida, corrigida e/ou ampliada (BALASCH; MONTENEGRO, 2003; MONCLÚS, 2011). Esse processo pode se repetir segundo interesse do pesquisador e participante da pesquisa, partindo-se do princípio de que nenhuma versão conseguirá esgotar todas as possibilidades. Ao final, dispõem de um texto elaborado e validado conjuntamente entre pesquisador e entrevistado, com contribuições para os meios sociais dos participantes da pesquisa e a comunidade científica (BALASCH; MONTENEGRO, 2003). Partindo desses pressupostos, a finalidade da investigação não é chegar a uma teoria universal, mas "abrir os espaços de compreensão e produção de significados, dando ênfase aos efeitos que se depreendem do conhecimento produzido" (GOIKOETXEA, 2014, p. 131).

\section{A metodologia das produções narrativas como ferramenta pedagógica para a licenciatura em educação do campo da Universidade Federal de Viçosa}

A produção narrativa realizada com Joana ${ }^{\text {ii }}$, para a realização desta pesquisa, foi articulada às atividades desenvolvidas por ela, em seu Plano de Estudos (PE), quando cursou o terceiro período do curso de Licenciatura em Educação do Campo, da Universidade Federal de Viçosa (LICENA). O Tema Gerador desse PE foi Territórios Educativos e, por isso, buscamos identificar e compreender os meios de vivência da entrevistada e, também, as principais organizações sociais e sindicais envolvidas com atividades educativas existentes em seu território de origem.

Durante a primeira entrevista narrativa, Joana apresenta suas impressões sobre o seu município de origem, Araponga, localizado na Zona da Mata de Minas Gerais. Em seu relato, Joana indica que esse município possui diversas organizações sociais, como a Escola Família Agrícola Puris (EFA - Puris), que é uma escola do campo que atua em regime de alternância; o Parque Estadual da Serra do Brigadeiro (PESB), uma unidade de preservação ambiental; a CRESOL, uma cooperativa de crédito rural solidário; o Centro de Pesquisa e Promoção Cultural (CEPEC), uma organização que desenvolve ações voltadas à valorização da cultura popular de Araponga e de municípios vizinhos; o Sindicato dos Trabalhadores Rurais de Araponga, organização social que tem auxiliado os agricultores familiares em suas lutas pelo acesso à terra e no fortalecimento da agricultura familiar. Dentre essas organizações sociais, Joana destaca a EFA - Puris, por ter sido a escola onde cursou o Ensino Médio e por ter oportunizado um processo de escolarização articulado às formas de trabalho e modos de vida dos agricultores familiares de seu município. A entrevistada reconhece, ainda, que as organizações sociais apresentadas possuem caráter educativo por serem espaços de formação de agricultores familiares e valorização de saberes e culturas populares.

Após a realização da primeira entrevista, Joana redige sua narrativa incluindo informações obtidas a partir de levantamentos realizados por ela com integrantes da EFA - 
Puris, do Sindicato dos Trabalhadores Rurais de Araponga - MG, da CRESOL e do CEPEC, a fim de resgatar a história, os principais objetivos, as principais ações desenvolvidas e as contribuições das organizações sociais existentes em seu município. É importante destacar que a primeira narrativa foi um texto contendo uma apresentação da própria participante e uma descrição do seu município em aspectos demográficos, sociais, climáticos e econômicos, apresentando, também, as organizações sociais destacadas na primeira entrevista. Destacamos que a primeira narrativa apresentou um volume significativo de informações, mas ficou despersonalizado em relação às experiências educativas da participante, como podemos observar no trecho a seguir.

Joana fez sua pesquisa em sua cidade de origem, Araponga - MG, cidade pequena
de oito a nove mil habitantes. Grande parte do município é zona rural e composta
por pequenos agricultores. Esse município é muito conhecido devido ao Parque
Estadual da Serra do Brigadeiro (PESB) e à cultura do café. No município também
tem uma Escola Família Agrícola, cujo nome é Escola Família Agrícola Puris (EFA
- Puris) devido aos índios que habitavam na região. Joana tem planos de estudar e
voltar para trabalhar e viver em Araponga. Joana tem como projetos futuros ajudar a
sua comunidade rural com cursos profissionalizantes (produção de mudas,
artesanatos, gado de leite, etc.) ajudando, desta forma, os agricultores se
autossustentarem no meio em que vivem, evitando a evasão dos jovens do meio
rural. Este sonho foi construído a partir de um sentimento de querer ajudar o lugar
de origem e foi reforçado no momento em que ela foi estudar na EFA - Puris, pelo
fato desta escola ter objetivos bem parecidos (JOANA).

Em relação ao trecho anterior, observamos que Joana relata sua investigação sobre os territórios educativos, mas não narra. Destacamos que em sua narrativa, Joana expressa o desejo de retornar à sua comunidade rural de origem após concluir o curso de Licenciatura em Educação do Campo, para promover melhorias nas condições de vida dos agricultores familiares de seu município, por meio do desenvolvimento de cursos profissionalizantes. A participante destaca que esse desejo foi reforçado no período em que estudou na EFA - Puris pois, segundo ela, esta escola tem o objetivo de contribuir para o desenvolvimento sustentável e solidário do campo, através da valorização das culturas camponesas e formas de trabalho dos agricultores familiares. Sob essas perspectivas, verificamos que ao identificar e conhecer as organizações sociais existentes em seu município, compreendendo sua importância para os sujeitos que vivem no meio rural, Joana tem sua identidade camponesa reafirmada, despertando o desejo de poder contribuir com o desenvolvimento de atividades que possam melhorar as condições de vida dos povos do campo em seu território educativo.

Ao lermos a primeira versão da narrativa, propusemos para a Joana a realização de uma segunda entrevista, a fim de constituir em sua narrativa a trajetória pessoal e as experiências educativas vivenciadas por ela a partir da infância. Nesta entrevista, a entrevistada narrou sua trajetória escolar, destacando as dificuldades vivenciadas por ela, seus irmãos e pessoas da sua comunidade para concluir o Ensino Fundamental. Tais dificuldades estavam relacionadas à mudança de escola para concluir os anos finais do Ensino Fundamental; às dificuldades de acesso à nova escola devido as precárias condições das estradas do meio rural; à ausência de transporte escolar em períodos chuvosos e à falta de merenda nas escolas, como podemos observar no trecho abaixo. 
Estudei até a quarta série na Escola Municipal José Gomes Sampaio, depois, se quiséssemos continuar nossos estudos tínhamos que ir estudar na Escola Estadual José Dias do Carmo, que está localizada em Estevão de Araújo, distrito de Araponga, a mais ou menos uns $17 \mathrm{~km}$ de minha casa. Neste caso, já não íamos mais a pé para a escola, íamos de ônibus. Eram, porém, cerca de 60 crianças ou mais dentro de um ônibus velho que cabia cerca de 40 alunos. Era muito apertado e sempre ficava muita gente em pé. Quando comecei a estudar na escola, ela era velha e a quadra era de terra e não tinha merenda escolar, e quando tinha, era um biscoito com suco de caixinha. Com o tempo reformaram a escola e construíram uma quadra nova, vários banheiros e começou a ter merenda de verdade (Arroz e feijão). Sempre que chovia não íamos à escola, pois a estrada era - e ainda é - de terra e tinha muito barro. Às vezes só chovia depois que chegávamos à escola, aí tínhamos que ir embora a pé, era a maior confusão. A minha irmã estudava à noite e todos os dias eu e minha mãe descíamos para o ponto de ônibus para esperar por ela, às vezes levávamos um cobertor porque fazia muito frio. Eu adorava quando minha mãe me chamava pra ir com ela. Às vezes, quando chovia, minha mãe ia a pé encontrar com ela, pois sabia que minha irmã estava vindo a pé da escola, era muito longe, e minha irmã tinha medo. Quando entrei para a sétima série, comecei a estudar à noite. Aí era pior ainda, pois só tinha adultos estudando à noite e eu ainda era uma criança. Me sentia muito perdida. Lembro que era horrível quando chovia, pois íamos embora a pé para casa e chegávamos cerca de meia-noite em casa (JOANA).

Observando o trecho anterior, destacamos que a narrativa redigida por Joana avançou em termos de coerência, investimento afetivo e personalização das informações, possibilitando identificar os espaços de formação mais significativos vivenciados por ela durante a infância e a adolescência, como as escolas em que concluiu os anos iniciais e finais do Ensino Fundamental, situadas, respectivamente, em sua comunidade de origem e em um distrito do município Araponga.

Após realizarmos a leitura da segunda versão da narrativa, sugerimos à participante da pesquisa que realizássemos uma terceira entrevista para identificarmos outros possíveis territórios educativos existentes, especialmente, em sua comunidade de origem. Durante essa entrevista, recomendamos que a entrevistada realizasse levantamentos junto aos moradores da comunidade para identificar outros espaços e processos educativos. Através desses levantamentos, Joana identificou quais foram as primeiras escolas da região, em que período elas surgiram e por quais motivos algumas delas foram fechadas. Identificou, ainda, que nem todos os moradores de sua comunidade rural tiveram a oportunidade de estudar e apresentou os caminhos percorridos pela maioria dos jovens que vivem ali para terem acesso à escola de educação básica. E, nesse contexto, a partir de suas experiências e vivências, reafirma a EFA Puris como um território educativo importante para o processo de escolarização dos agricultores familiares do município, por desenvolver um trabalho pedagógico articulado às formas de trabalho, aos modos de vida e às culturas camponesas, como apresentado no trecho seguinte.

Rosa $^{\text {iii }}$ acredita que foi por volta 1985 que surgiram as primeiras escolas municipais na região. As primeiras professoras eram filhas de fazendeiros, pois eram as únicas que tinham a oportunidade de estudar. As escolas que foram construídas eram de $1^{\circ}$ a $4^{\circ}$ série, elas se chamavam Escola Municipal Jose Gomes Sampaio, na comunidade Córrego das Bestas, Escola Municipal Rita Correia de Lima construída na comunidade da Barra e a Escola Municipal Antônio Candido Gomes, na comunidade Tromba D'Anta. Atualmente, apenas uma destas escolas se encontra aberta: a Escola Municipal Rita Correia de Lima. Devido à falta de alunos, 
passaram todas as crianças para apenas uma escola, tendo como forma de condução os micro-ônibus. Após as crianças completarem o primário, passam a estudar em Estevão de Araújo o seu Ensino Fundamental e Médio, tendo também a EFA - Puris fornecendo o Ensino Médio com o curso Técnico em Agropecuária, localizada em Araponga, porém em outro povoado que se chama São Joao Joaquim [...]. É o anseio dos agricultores que a EFA - Puris de Araponga possa ser mais que uma escola, que seja um instrumento de desenvolvimento nas mãos dos (as) agricultores (as) que venha a considerar as dimensões da educação para a cidadania; as relações existentes entre os diferentes atores do processo e os diversos saberes dos trabalhadores do campo, tão necessários para a compreensão e a atuação no meio rural. [...]. Foi na EFA - Puris que estudei o Ensino Médio e me formei lá. Eu adquiri experiências e aprendizados, fazendo com que eu, nascida e criada no campo, pudesse valorizar mais o meio em que eu nasci. Foi a EFA que me incentivou a estudar e ter sempre como objetivo voltar para meu lugar de origem (JOANA).

Ao avaliar a terceira versão da narrativa de Joana, destacamos que a participante conseguiu articular as suas experiências pessoais aos contextos históricos de sua comunidade e município. A sua narrativa identificou inúmeros territórios educativos, dentre os quais, evidenciamos as organizações sociais identificadas ainda na primeira versão da narrativa. Dentre as organizações sociais, destacamos a EFA - Puris como um importante território educativo no município de Araponga, pois tem possibilitado que os jovens que vivem no campo, a exemplo de Joana, tenham acesso a um processo de escolarização articulado aos contextos sociais vivenciados por ela em sua comunidade rural de origem. Destacamos, ainda, que a EFA - Puris apresenta-se com uma alternativa às mazelas vivenciadas por Joana e por outros moradores de sua comunidade ao longo das suas trajetórias escolares no meio rural, como fechamento das escolas do campo, falta de merenda e ausência de transporte escolar para os povos camponeses. Sob essas perspectivas, a narrativa de Joana ancora-se nos princípios de parcialidade e de conhecimentos situados ao apresentar saberes parciais construídos a partir das experiências vivenciadas por ela no contexto de uma comunidade rural situada no município de Araponga.

Verificamos, ainda, que as narrativas produzidas por Joana encontram proximidade com os pressupostos de formação por área de conhecimentos da Educação do Campo, uma vez que permite não apenas uma compreensão ampliada da realidade, mas uma relação identitária e reflexiva sobre o contexto no qual os educandos se encontram (MOLINA, 2017). $\mathrm{Na}$ perspectiva da formação por área de conhecimento, a apropriação das ferramentas de pesquisa e produção de conhecimento conforme demonstrado por Joana, uma futura educadora, prepara-a para o exercício de uma formação permanente, uma metodologia da aprendizagem e da ação, como descreve Gimonet (2007) sobre o Plano de Estudos.

Enquanto ferramenta pedagógica, a Metodologia de Produções Narrativas encontra-se em acordo com a discussão sobre o lugar da educação na contemporaneidade, superando a falsa dicotomia, na qual, por um lado, estaria a defesa do acesso ao conhecimento universal, por outro, evitar o desperdício da experiência e os saberes silenciados de grupos minoritários.

A superação desta dicotomia está pressuposta nos fundamentos dos processos de formação em alternância, ao fortalecer as experiências e necessidades dos educandos e sua comunidade como possibilidade para o desenvolvimento da técnica. A teoria dos conhecimentos situados radicaliza este pressuposto ao legitimar o existente, inseri-lo em 
espaços dialógicos e sintetizá-lo a partir do contato com outros saberes existentes. Sob essas perspectivas, as produções narrativas de Joana assumem esse movimento ao historicizar-se, ou seja, ao reconhecer as forças motrizes da história de seu contexto, seus rumos e seus sujeitos.

\section{Algumas considerações}

O processo de formação em alternância desenvolvido nas Licenciaturas em Educação do Campo tem como principal objetivo formativo promover estratégias educativas que articulem as experiências vivenciadas pelos educandos em suas comunidades e territórios de origem com os processos de formação vivenciados no âmbito destes cursos (MOLINA; SÁ, 2011). Busca-se, com isso, estimular os educandos a refletirem sobre as realidades sociais em que se inserem e a propor ações que possibilitem melhorias nas condições de vida dos povos camponeses (MOLINA; ANTUNES-ROCHA, 2014).

Considerando essas informações, o presente artigo avaliou as possíveis contribuições da Metodologia das Produções Narrativas como uma estratégia a ser utilizada no processo de formação das Licenciaturas em Educação do Campo, considerando sua capacidade em articular as trajetórias subjetivas dos educandos aos contextos históricos e sociais de seus territórios educativos (FANTASIA; LEITE, 2013). Para tanto, utilizamos a Metodologia das Produções Narrativas como uma ferramenta pedagógica no curso de Licenciatura em Educação do Campo (LICENA) da Universidade Federal de Viçosa para a realização do Plano de Estudos Temáticos sobre os Territórios Educativos. O método de estudo de caso foi utilizado como referência para a produção de narrativas, tendo sido desenvolvido com uma educanda da LICENA.

É possível perceber que a Metodologia das Produções Narrativas apresenta contribuições significativas para o desenvolvimento dos Planos de Estudos. Destacamos a princípio que as narrativas produzem um volume significativo de material sobre situações concretas da educação do campo, tendo importante função documental.

Destacamos também que a produção textual da participante da pesquisa, a partir de sua narrativa, foi ampliada em termos de coerência e consistência na interação com o entrevistador/pesquisador. Embora a pesquisa não desenvolvesse critérios para a avaliação aprofundada sobre as contribuições nesse quesito, este não deixou de ser observado, comentado e orientado na leitura das narrativas, em concordância com os princípios da formação integral que orienta a Educação do Campo. Passa a ser, portanto, questão relevante a ser aprofundada em pesquisas futuras.

Em termos formativos, a Metodologia das Produções Narrativas contribui significativamente com a proposta do Plano de Estudos, que tem por objetivo a produção e acesso ao conhecimento, a partir da utilização de instrumentos investigativos, também denominado como letramento científico.

Em relação ao tema proposto pelo Plano de Estudos, a saber, os Territórios Educativos, as narrativas produzidas evidenciaram que, ao refletir sobre as instituições 
educativas, seu histórico e sua importância na constituição dos territórios educativos de seu município de origem, Joana foi capaz de ampliar a sua compreensão sobre os contextos sociais em que vive, o papel dos integrantes de sua comunidade neste processo e a importância da educação na formação dos mesmos. Podemos destacar, ainda, que esta compreensão favoreceu em Joana a reafirmação de sua identidade camponesa e seu desejo de contribuir para o desenvolvimento de ações desenvolvidas em seu território educativo.

Retomando a questão que norteou a proposta de pesquisa, a saber, as contribuições da Metodologia das Produções Narrativas como ferramenta pedagógica da LICENA, os resultados aqui apresentados permitem inferir que a utilização desta metodologia favorece a articulação entre saberes experienciais e saberes acadêmicos, adequando-se ao instrumental utilizado pela formação em alternância, com especial destaque para o Plano de Estudos. Esta articulação pode ser observada não apenas na compreensão dos processos históricos de construção dos territórios educativos por parte de Joana, mas também na mobilização pessoal, na manifestação de identidade com o território demonstrada por ela ante esta descoberta.

Não obstante, pensar a Metodologia das Produções Narrativas como ferramenta pedagógica não pressupõe que possa ser utilizada isoladamente. A partir dos resultados obtidos com este estudo de caso, acreditamos que este processo de aprendizagem pode ser potencializado a partir de sua articulação com as demais ferramentas educativas utilizadas nos cursos de Licenciatura em Educação do Campo, como a Colocação em Comum, por exemplo. Consideramos que o aprofundamento das informações sobre os territórios educativos produzidos nas narrativas enriqueceria os debates entre diferentes sujeitos do campo e suas experiências. Sob essa perspectiva, a socialização dessas experiências durante a Colocação em Comum, ampliaria a compreensão dos educandos sobre a realidade do campo, os elementos fundamentais para o desenvolvimento dos territórios educativos e as desigualdades entre eles, configurando-se como um espaço profícuo de aprendizagem e preparo para a intervenção. Os conhecimentos produzidos a partir destes embates, sintetizados em seus Cadernos de Realidade, como um registro individual, mas, problematizado coletivamente, apresentaria um registro complexo e dinâmico das diferentes realidades do campo brasileiro e seus atores, permitindo a sistematização de intervenções fundamentadas.

Durante a elaboração das produções narrativas, o movimento de idas e vindas, provocados pelo pesquisador/educador nas Colocações em Comum, incitam o educando narrador a um processo reflexivo e potencializa os conhecimentos produzidos, oferecendolhes fluxos distintos de experiências e informações de acordo com as necessidades emergentes. Esperamos que, ao utilizar a Metodologia das Produções Narrativas como ferramenta pedagógica nas Licenciaturas em Educação do Campo, este movimento desencadeie fluxos multidirecionais de conhecimento e ação, seja para os pesquisadores/educadores, que estabelecerão correlações com suas atividades de docência, extensão e pesquisa, seja para os educandos que, da intencionalidade original de levantamento de informações ao processo de organização, reflexão e reelaboração das discussões coletivas, avancem significativamente em suas narrativas. Neste sentido, é uma expectativa para as próximas pesquisas que as narrativas se apresentem como material 
pedagógico sobre os territórios educativos onde os educandos vivem, como um cenário no qual estas e uma multiplicidade de outras informações, se imiscuirão na construção de um mapa dos territórios educativos do Campo: uma tessitura em movimento.

\section{Referências}

BAKHTIN, Mikhail. Marxismo e Filosofia da Linguagem. São Paulo, Hucitec, 1981.

BALASCH, Marcel; MONTENEGRO, Marisela. Una propuesta metodológica desde la epistemología de los conocimientos situados. Las producciones narrativas. Encuentros en Psicología Social, v. 1, n. 3, 44-48, 2003.

CARVALHO, Josiane das Graças; SILVA, Lourdes Helena da. Alternance in the formation of countryside educators: looking for markers in the academic productions and social representations of education students. Revista tempos e espaços em educação. São

Cristovão, v. 11, n. 26, p. 339-350, jul./set. 2018.

FANTASIA, Ana; LEITE, Pedro Pereira. As narrativas biográficas e os processos de investigação-ação sobre memória e esquecimento. Revista de Práticas de Museologia Informal, n. 2, p. 50-60, Spring 2013.

GIMONET, Jean-Claude. Praticar e compreender a pedagogia da alternância dos CEFFAs. Petrópolis/RJ: Vozes, 2007.

GOIKOETXEA, Itziar Gandarias. Tensiones y distensiones en torno a las relaciones de poder en investigaciones feministas con Producciones Narrativas. Quaderns de Psicologia. Barcelona, v. 16, n. 1, p. 127-140, 2014.

HARAWAY, Donna J. Ciencia, Cyborgs y Mujeres: la reinvención de la naturaleza. Madrid: Ediciones Cátedra, 1995.

MOLINA, Mônica Castagna. Contribuições das licenciaturas em educação do campo para as políticas de formação de educadores. Educação \& Sociedade. Campinas, v. 38, n. 140, p. 587-609, jul./set. 2017.

MOLINA, Mônica Castagna. Expansão das licenciaturas em Educação do Campo: desafios e potencialidades. Educar em Revista. Curitiba, n. 55, p. 145-166, jan./mar. 2015.

MOLINA, Mônica Castagna; ANTUNES-ROCHA, Maria Isabel. Educação do Campo, história, práticas e desafios no âmbito das políticas de formação de educadores - reflexões sobre o PRONERA e o PROCAMPO. Revista Reflexão e Ação. Santa Cruz do Sul, v. 22, n. 2, p. 220-253, jul./dez. 2014.

MOLINA, Mônica Castagna; SÁ, Laís Mourão. A Licenciatura em educação do campo da universidade de Brasília: estratégias político-pedagógicas na formação de educadores do campo. In: MOLINA, Mônica Castagna; SÁ, Laís Mourão (org.). Licenciatura em

Educação do Campo: Registros e reflexões a partir das experiências-piloto (UFMG, UnB, UFBA e UFS). 1 ed. Belo Horizonte: Autêntica, 2011, p. 35-62. 
MONCLÚS, Pamela Loreto Gutiérrez. Terapia Ocupacional: Una disciplina para la autonomía. Prácticas y discursos de Gubernamentalidad y subjetivación en torno a una ciencia emergente. 2011. 368f. Tese (Doutorado em Psicologia Social) - Universidad Autónoma de Barcelona, Barcelona, 2011.

MARTÍNEZ, Marisela Montenegro; TARRÉS, Joan Pujol i. Conocimiento situado: un forcejeo entre el relativismo construccionista y la necesidad de fundamentar la acción.

Revista Interamericana de Psicología. v. 2, n. 37, p. 295-307, 2003.

SANTOS, Clarice Aparecida dos. Educação do campo e políticas públicas no Brasil: o protagonismo dos movimentos sociais do campo na instituição de políticas públicas e a licenciatura em educação do campo na UnB. Brasília: Líber Livro; Faculdade de Educação/UnB, 2012.

UFV. Universidade Federal de Viçosa. Projeto Pedagógico: curso de licenciatura em educação do campo. Viçosa, Minas Gerais, 2013.

\section{Notas}

\footnotetext{
${ }^{i}$ Esse artigo é resultado de pesquisa realizada durante o estágio pós-doutoral (CAPES BEX 1922/14-9), discutida, aprofundada e finalizada com equipe da pesquisa "Metodologia das Produções Narrativas como Ferramenta Pedagógica para o Curso de Licenciatura em Educação do Campo da Universidade Federal de Viçosa", financiada pela FAPEMIG (CHE APQ 01172-15).

${ }^{i i}$ Nome fictício para preservar a identidade da participante da pesquisa.

iii Nome fictício.
} 